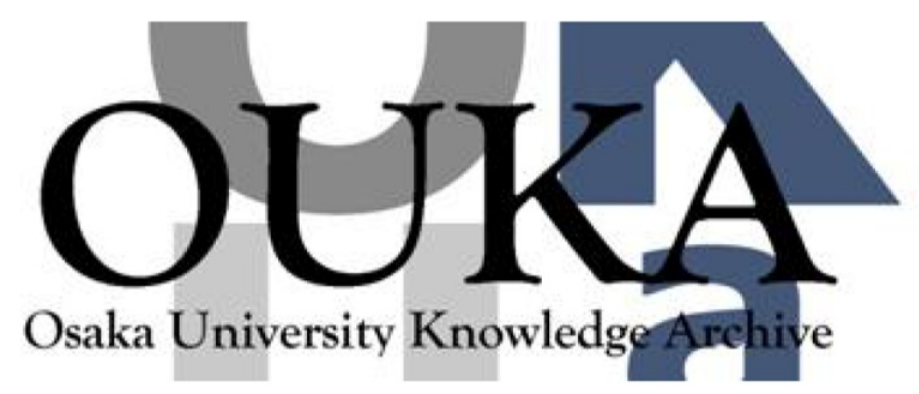

\begin{tabular}{|c|l|}
\hline Title & $\begin{array}{l}\text { Extracellular calcium protects cultured rat } \\
\text { hepatocytes from injury caused by hypothermic } \\
\text { preservation }\end{array}$ \\
\hline Author(s) & Umeshita, Koji \\
\hline Citation & \\
\hline Issue Date & \\
\hline oaire:version & VoR \\
\hline URL & https://hdl. handle. net/11094/36600 \\
\hline rights & \\
\hline Note & \\
\hline
\end{tabular}

Osaka University Knowledge Archive : OUKA

https://ir. Library. osaka-u. ac. jp/

Osaka University 


\title{
Extracellular Calcium Protects Cultured Rat Hepatocytes from Injury Caused by Hypothermic Preservation
}

\author{
KOJI UMESHITA, MORITO MONDEN, TSUGIKATSU FUJIMORI, \\ HIDEYUKI SAKAI, MITSUKAZU GOTOH, JUN OKAMURA, AND \\ TAKESADA MORI \\ Department of Surgery, Osaka University Medical School, Fukushima-ku, Osaka 553, Japan
}

\begin{abstract}
Effects of various preservation solutions were compared in an experimental hypothermic preservation model using cultured rat hepatocytes. Hepatocytes prepared by the collagenase perfusion method were cultured for $48 \mathrm{hr}$, then the medium in each culture dish was exchanged for various preservation solutions, and the dishes were hypothermically $\left(0-2^{\circ} \mathrm{C}\right)$ stored in a refrigerator for $12-72 \mathrm{hr}$. After the preservation period, the hepatocytes were cultured again at $37^{\circ} \mathrm{C}$ for $2 \mathrm{hr}$. Hepatocytes' viability after 18-hr preservation and reculture was greater when they were preserved in "intracellular" rather than "extracellular" solutions. Even with Euro-Collins solution (intracellular solution), hepatocyte viability decreased to approximately $20 \%$ after $24-\mathrm{hr}$ preservation, and an increase in the cellular lipid peroxide content was observed. However, when this solution contained a submillimolar concentration of calcium, lipid peroxidation was significantly suppressed and hepatocyte viability was dramatically improved. Vitamin $\mathbf{E}$ was almost equally effective and a marked synergistic effect was observed with calcium. Calcium was found to be capable of maintaining the cellular glutathione level during cold storage, which seems to suppress lipid peroxidation and consequently improve hepatocyte survival. (1988 Academic Press, Inc.
\end{abstract}

The so-called "intracellular" solutions, with electrolyte compositions resembling those of intracellular fluid, are employed as preservation solution in various organ transplantations, including those of the kidncy and liver $(3,23)$. These solutions are commonly considered to be superior to "extracellular" solutions. Yet, even with these intracellular solutions, the preservation time for successful organ transplantation is rather short. For example, the liver can be safely preserved only for $6-8 \mathrm{hr}$ in clinical transplantation (22), though successful preservation for 24 and $48 \mathrm{hr}$ has been reported with canine experimental models (16). Prolongation of the preservation time should promote more effective utilization of donated organs. For this purpose, various modifications of the preservation solution (electrolyte composition

Received July 6, 1987; accepted September 11, 1987. and additives) have been used in experimental and clinical transplantations. Some of these efforts have been reported to be very effective, but evaluations frequently differ and sometimes are even contradictory. The problem is in the method of judging the preservation results. The survival rate of the recipient is, of course, the ultimate method of examining the viability of transplanted organs, but it is not always reproducible because of different animal conditions and technical problems. We therefore developed a simple and reproducible model system of hypothermic liver preservation using cultured rat hepatocytes. In this model, many uniform samples can be obtained from one liver and many different treatments can be tested simultaneously. Moreover, the effect of the treatments on only the liver cells can be examined, apart from the effect on the vascular system.

Calcium has been suggested to play an important role in the course of cell injury 
caused by ischemia and reperfusion or toxins (26). There exists a very steep gradient of calcium on both sides of the plasma membrane. The calcium concentration in the extracellular fluid is around $10^{-3} \mathrm{M}$, and the intracellular concentration of hepatocytes is reported to be about $2 \times$ $10^{-7} M(2,17)$. This gradient is maintained by the low permeability of the plasma membrane and by active calcium transport systems, which use energy. ATP depletion caused by cessation of the blood stream leads to massive influx of calcium into a cell (13) and finally provokes cell death. Thus, extracellular calcium may be considered to be harmful in ischemic cell injury. In the field of organ transplantation, most of the preservation solutions used today are calcium free. However, in this study, we observed that addition of a submillimolar level of calcium could dramatically protect hepatocytes from hypothermic injury. The mechanism of this protective effect was examined.

\section{MATERIALS AND METHODS}

Isolation and culture of rat hepatocytes. Hepatocytes from male Wistar rats, which weighed 180-300 $\mathrm{g}$ and were fed ad $l i$ bitum, were prepared by the collagenase perfusion method as modified from Seglen (20). The rats were anesthetized with ether and heparinized. After the liver was skeletonized, a catheter was inserted into the portal vein and the liver was washed out with $50 \mathrm{ml}$ of calcium-free Eagle's minimum essential medium (MEM) supplemented with $5 \mathrm{~m} M$ of EGTA. The liver was removed and perfused with Eagle's MEM medium with $0.8 \mathrm{mg} / \mathrm{ml}$ of collagenase (Wako Pure Chemical, Japan) and $5 \mathrm{mM}$ of calcium in a closed circuit at $37^{\circ} \mathrm{C}$ bubbled with $\mathrm{O}_{2}$ for $10 \mathrm{~min}$. Next, the liver was dispersed gently by forceps in the medium. Purification was done by three cycles of centrifugation and filtration, and then the hepatocytes were suspended in Williams' $E$ medium at $5 \times 10^{5}$ cells $/ \mathrm{ml}$. The viability of the hepatocytes prepared in this way was over $90 \%$. A $1.5-\mathrm{ml}$ portion of the suspension was poured into each culture dish (35 $\mathrm{mm}$ in diameter; Falcon) and cultured in a $\mathrm{CO}_{2}$ incubator at $37^{\circ} \mathrm{C}$ for $2 \mathrm{hr}$. As viable hepatocytes attached to the bottom of the dish during this period, each dish was rinsed with $1 \mathrm{ml}$ of warm calcium-free culture medium to remove dead cells. Then the hepatocytes were cultured in Williams' E medium for $48 \mathrm{hr}$ before the preservation experiment.

Preservation experiment. The culture medium of each dish was replaced with the preservation solution at room temperature. The dishes were stored in a refrigerator at $0-2^{\circ} \mathrm{C}$ for 12 to $72 \mathrm{hr}$. Rat serum, Williams' E culture medium, lactated Ringer's solution, and Euro-Collins solution with various concentrations of calcium, magnesium, and vitamin E were used as preservation solutions (Table 1). As much as $0.8 \mathrm{mM}$ calcium $\left(\mathrm{CaCl}_{2}\right)$ was soluble in Euro-Collins solution. Vitamin E was dissolved in dimethyl sulfoxide at $2.5 \mathrm{mM}$ and an adequate amount of this solution was added to Euro-Collins solution. After cold storage, the preservation solution of each dish was exchanged for Williams' $E$ culture medium and hepatocytes were recultured in a $\mathrm{CO}_{2}$ incubator at $37^{\circ} \mathrm{C}$ for $2 \mathrm{hr}$. At the end of reculture, we assayed the viability, the lipid peroxide content, the glutathione content of the hepatocytes, and the lactate dehydrogenase ( $\mathrm{LDH})$ activity released into the preservation solution and the culture medium. Hepatocyte viability was measured by $0.01 \%$ trypan blue exclusion test. Cellular lipid peroxide content was measured by the thiobarbituric acid (TBA) reaction after being solubilized with sodium dodecyl sulfate, according to Masugi et al. (15). Cellular glutathione (GSH + GSSG) content was measured by the enzymatic method by Tietze (25). LDH activity was measured enzymatically with Unikit (Chugai, Japan). 
TABLE 1

Composition of the Preservation Media

\begin{tabular}{lcccr}
\hline & Rat serum & $\begin{array}{c}\text { Williams' } \\
(27)\end{array}$ & $\begin{array}{c}\text { Lactated } \\
\text { Ringer's }\end{array}$ & Euro-Collins \\
\hline $\mathrm{Na}^{+}$ & 145 & 143 & 130 & 10 \\
$\mathrm{~K}^{+}$ & 4.5 & 5.3 & 4.0 & 115 \\
$\mathrm{Ca}^{2+}$ & 5.0 & 3.6 & 3.0 & 0 \\
$\mathrm{Mg}^{2+}$ & 1.6 & 1.6 & 0 & 0 \\
$\mathrm{Cl}^{-}$ & 105 & 125 & 109 & 15 \\
$\mathrm{HCO3}^{-}$ & 25 & 26 & 0 & 10 \\
Phosphate & 7.7 & 1.0 & 0 & 100 \\
Sulfate & - & 1.6 & 0 & 0 \\
Glucose (g/liter) & 2 & $1.99^{a}$ & 0 & 35 \\
Protein (g/liter) & 65 & 0 & 0 \\
\hline
\end{tabular}

Note. Concentrations are $\mathrm{mEq} /$ liter unless indicated otherwise.

a Total amino acid.

\section{RESULTS}

Hepatocyte viabilities after 18 -hr preservation with rat serum, Williams' $E$ culture medium, lactated Ringer's solution, and Euro-Collins solution were 6, 4, 35, and $82 \%$, respectively (Table 2 ). The intracellular solution was obviously superior to the extracellular solutions in this system as in vivo transplantation.

Hepatocyte viability after 24 -hr preservation with Euro-Collins solution was $18 \%$. Addition of calcium $(0.2-0.8 \mathrm{~m} M)$ significantly improved hepatocyte survival $(P<$ $0.01)$. LDH activity released into the preservation solution and into the culture medium was significantly $(P<0.01)$ greater when preserved with Euro-Collins solution without calcium $\left(3068 \pm 123\right.$ unit $/ 10^{6}$ cells $)$ than that with $0.8 \mathrm{~m} M$ calcium $(61 \pm 49$ unit $/ 10^{6}$ cells). Cellular lipid peroxide content after 24-hr preservation with EuroCollins solution and $2-\mathrm{hr}$ reculture was $510 \%$ of the prepreservation values. Those with Euro-Collins solution with 0.2 and $0.8 \mathrm{~m} M$ of calcium were 430 and $290 \%$. Thus, calcium suppressed the lipid peroxidation during preservation and reculture and improved hepatocyte viability (Table 3).

Magnesium at $0.2,0.4$, and $0.8 \mathrm{mM}$, which was added as $\mathrm{MgCl}_{2}$, improved he- patocyte viability after $24-\mathrm{hr}$ preservation to 25,30 , and $32 \%$, but was less effective than calcium.

Addition of $50 \mu M$ of vitamin $\mathrm{E}$ improved the hepatocyte viability after $24-\mathrm{hr}$ preservation and 2-hr reculture to $96 \%$ and depressed lipid peroxide content. The combination of $50 \mu M$ of vitamin $\mathrm{E}$ and $0.8 \mathrm{mM}$ of calcium suppressed lipid peroxide content even more (Table 4). DMSO itself, which was used as the carrier of vitamin $E$, improved hepatocyte viability to $30 \pm 5 \%$,

TABLE 2

Effect of Extracellular and Intracellular Solutions

\begin{tabular}{llc}
\hline \multicolumn{2}{c}{ Preservation solution } & $\begin{array}{c}\text { Hepatocyte } \\
\text { viability (\%) }\end{array}$ \\
\hline $\begin{array}{c}\text { Extracellular } \\
\text { solutions }\end{array}$ & Rat serum & $6 \pm 2^{*}$ \\
& $\begin{array}{c}\text { Williams' E } \\
\text { culture medium } \\
\text { Lactated Ringer's } \\
\text { solution } \\
\text { Intracellular } \\
\text { solution }\end{array}$ & $\begin{array}{c}\text { Euro-Collins } \\
\text { solution }\end{array}$ \\
\hline
\end{tabular}

Note. Hepatocyte viability after 18 -hr preservation and 2 -hr reculture. Values are means $\pm \mathrm{SD} ; n=4$ in all groups.

* S' 'istically different $(P<0.001)$ from EuroCollins solution.

** Statistically different $(P<0.01)$ from EuroCollins solution. 
TABLE 3

Effect of Calcium on Hepatocyte Viability and Lipid Peroxide Content

\begin{tabular}{lccc}
\hline & $\begin{array}{c}\text { Calcium concentration } \\
(\mathrm{mM})\end{array}$ & $\begin{array}{c}\text { Hepatocyte viability } \\
(\%)\end{array}$ & $\begin{array}{c}\text { TBA reactant } \\
\left(\mathrm{nmol} / 10^{6} \mathrm{cells}\right)\end{array}$ \\
\hline Control & - & $98 \pm 2$ & $2.09 \pm 0.21$ \\
After preservation & 0 & $18 \pm 3^{*}$ & $10.76 \pm 2.56^{*}$ \\
& 0.2 & $42 \pm 6^{* *}$ & $9.04 \pm 0.96$ \\
& 0.4 & $55 \pm 5^{* * *}$ & N.D. \\
& 0.6 & $57 \pm 3^{* * *}$ & N.D. \\
& 0.8 & $96 \pm 2^{* *}$ & $6.11 \pm 0.71^{* *}$ \\
\hline
\end{tabular}

Note. Hepatocyte viability and lipid peroxide content after 24 -hr preservation and 2 -hr reculture. Values are means $\pm \mathrm{SD} ; n=4$ in all groups. N.D., not done.

* Statistically different $(P<0.001)$ from control.

** Statistically different $(P<0.01)$ from $0 \mathrm{~m} M$ calcium.

*** Statistically different $(P<0.001)$ from $0 \mathrm{~m} M$ calcium.

* Statistically different $(P<0.05)$ from control.

*\# Statistically different $(P<0.05)$ from $0 \mathrm{~m} M$ calcium.

but was significantly less effective than vitamin E carried by DMSO $(P<0.01)$.

Hepatocyte viability after 30 -hr preservation and 2-hr reculture with Euro-Collins solution was $1 \%$. Addition of 1 and $5 \mu M$ of vitamin $\mathrm{E}$ improved this to 11 and $42 \%$. Hepatocyte viability reached a plateau over this concentration. Addition of $0.8 \mathrm{mM}$ of calcium significantly improved hepatocyte survival, compared with vitamin $\mathrm{E}$ alone (Fig. 1; $\boldsymbol{P}<\mathbf{0 . 0 1}$, for each vitamin $\mathrm{E}$ concentration).

Figure 2 shows the time course of hepatocyte viability after 12 - to 72 -hr preservation with four different solutions. With Euro-Collins solution, $99 \%$ of the hepatocytes died within $36 \mathrm{hr}$. Calcium at $0.8 \mathrm{mM}$ or vitamin $\mathrm{E}$ at $50 \mu \mathrm{M}$ almost equally prolonged hepatocyte survival, but their combination was even more effective.

Table 5 shows the glutathione (GSH + GSSG) content after 15- and 24-hr preservation with Euro-Collins solution with or without calcium. During preservation with Euro-Collins solution, the cellular glutathione content decreased steadily, but $0.8 \mathrm{~m} M$ of calcium could keep it at a significantly higher level $(P<0.001$, both 15 and $24-\mathrm{hr}$ preservation).

\section{DISCUSSION}

Much recent work has been done to clarify the mechanism of hepatocyte death from various causes, including toxins, isch-

TABLE 4

Synergistic Effect of Calcium and Vitamin E on Hepatocyte Lipid Peroxide Content

\begin{tabular}{cccc}
$\begin{array}{c}\text { Calcium concentration } \\
(\mathrm{m} M)\end{array}$ & $\begin{array}{c}\text { Vitamin } \begin{array}{c}\mathrm{E} \text { concentration } \\
(\mu M)\end{array} \\
\begin{array}{c}\text { Hepatocyte viability } \\
(\%)\end{array}\end{array}$ & $\begin{array}{c}\text { TBA Reactant } \\
\left(\mathrm{nmol} / 10^{6} \text { cells }\right)\end{array}$ \\
\hline 0 & 0 & $18 \pm 3$ & $10.76 \pm 2.56$ \\
0 & 50 & $96 \pm 2^{*}$ & $4.31 \pm 0.08^{* *}$ \\
0.8 & 50 & $96 \pm 2^{*}$ & $1.56 \pm 0.29^{* * *}$ \\
\hline
\end{tabular}

Note. Hepatocyte viability and lipid peroxide content after 24 -hr preservation and 2-hr reculture. Values are means $\pm \mathrm{SD} ; n=4$ in all groups.

* Statistically different $(P<0.001)$ from $0 \mathrm{~m} M$ calcium $+0 \mu M$ vitamin $\mathrm{E}$

** Statistically different $(P<0.05)$ from $0 \mathrm{~m} M$ calcium $+0 \mu M$ vitamin $\mathrm{E}$.

*** Statistically different $(P<0.001)$ from $0 \mathrm{~m} M$ calcium $+50 \mu M$ vitamin $\mathrm{E}$ 


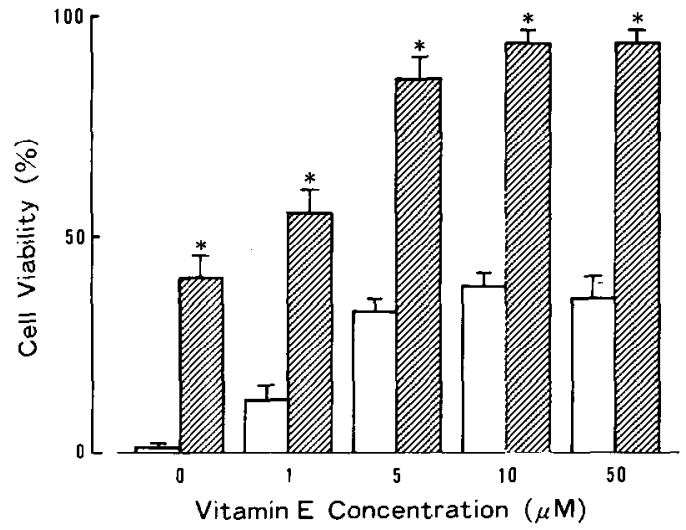

FiG. 1. Hepatocyte viability after 30 -hr preservation and 2-hr reculture. Open bars show hepatocyte viability preserved only with various concentrations of vitamin $\mathrm{E}$. Hatched bars show those with both vitamin $E$ and $0.8 \mathrm{~m} M$ of calcium. ${ }^{*}$ Statistically different $(P<0.01)$ from calcium $(-)$ at each vitamin $E$ concentration.

emia, and anoxia. It is suggested that impaired calcium homeostasis may be the final common pathway of cell death from these causes $(19,26)$. To clarify the mechanism of cell death, isolated or cultured cells are often employed as the experimental model. Schanne et al. (19) demonstrated that $\mathbf{1 0}$ different chemicals, which were known to interact with cell membranes, killed cultured rat hepatocytes only when extracellular calcium was present. This indicated that loss of cell membrane integrity caused calcium influx, which led to cell death. On the other hand, Smith et al. (21) reported that three hepatotoxins injured isolated rat hepatocytes only in the absence of extracellular calcium. Thus, the role of extracellular calcium in toxic cell death is conflicting. We previously reported that hepatocyte injury caused by anoxic culture was strictly related to the calcium concentration of the culture medium. A low concentration $(0.3-0.6 \mathrm{mM})$ of calcium protected hepatocytes from cell death, but concentrations above or below this accelerated cell death (8).

In the field of organ preservation, the effect of calcium in preservation solutions had not been examined. Our results clearly demonstrated that injury of cultured hepatocytes by hypothermic $\left(0-2^{\circ} \mathrm{C}\right)$ preservation could be prevented by extracellular calcium. The protective effect paralleled the calcium concentration in the range of 0.2-0.8 $\mathrm{m} M$ (maximal soluble concentration). Hepatocytes were also protected from hypothermic injury by vitamin $E$, which is an antioxidant (24).

Hepatocyte lipid peroxide content after 24-hr cold storage and 2-hr reculture decreased as the calcium concentration of the

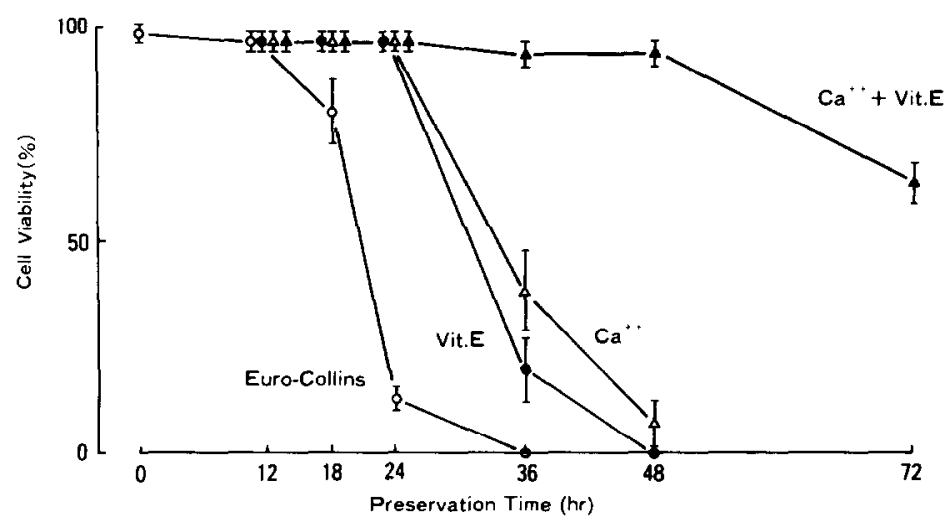

FIG. 2. Hepatocyte viability after 12- to 72-hr preservation and 2-hr reculture. (O) Euro-Collins solution, $(\odot)+50 \mu M$ of vitamin $\mathrm{E},(\Delta)+0.8 \mathrm{~m} M$ of calcium, $(\Delta)+50 \mu M$ of vitamin $\mathrm{E}$ and $0.8 \mathrm{~m} M$ of calcium. 
TABLE 5

Effect of Calcium on Hepatocyte Glutathione Content

\begin{tabular}{cccc}
\hline $\begin{array}{c}\text { Preservation time } \\
\text { (hr) }\end{array}$ & Calcium & $\begin{array}{c}\text { GSH }+ \text { GSSG } \\
\left(\mathrm{nmol} / 10^{6} \text { cells }\right)\end{array}$ & $\begin{array}{c}\text { Hepatocyte viability } \\
(\%)\end{array}$ \\
\hline Control & - & $27.6 \pm 2.2$ & $98 \pm 2$ \\
15 & $(-)$ & $11.7 \pm 1.1^{*}$ & $98 \pm 3$ \\
& $(+)$ & $26.2 \pm 1.8^{* *}$ & $98 \pm 2$ \\
24 & $(-)$ & $6.0 \pm 1.3^{*}$ & $18 \pm 3$ \\
& $(+)$ & $24.1 \pm 2.1^{* *}$ & $95 \pm 3$ \\
\hline
\end{tabular}

Note. Hepatocyte glutathione content after 15 - or 24-hr preservation with Euro-Collins solution with or without extracellular calcium $(0.8 \mathrm{~m} M)$. Values are means $\pm \mathrm{SD} ; n=4$ in all groups.

* Statistically different $(P<0.001)$ from control.

** Statistically different $(P<0.001)$ from calcium $(-)$ for each preservation time.

preservation solution increased. This suggested that extracellular calcium may exert its protective effect on hepatocytes through suppression of lipid peroxidation during hypothermic preservation and reculture. Because hepatocyte viability decreased as extracellular calcium was reduced, the increase of lipid peroxidation may be considered to be simply the result of hepatocyte death. However, hepatocytes preserved with both $0.8 \mathrm{mM}$ of calcium and $50 \mu M$ of vitamin $\mathrm{E}$ contained less lipid peroxide than those preserved with $50 \mu M$ of vitamin $\mathrm{E}$ alone, though the viabilities of both were $96 \%$. This finding indicates that lipid peroxidation is not merely the result of hepatocyte death by cold storage and reculture, but may be causally related to hypothermic injury. It is considered today that membrane attack and lipid peroxidation by oxygen-free radicals may be important in tissue injury in organ preservation and transplantation $(11,18)$, as in the case of normothermic ischemia and reperfusion (10), and our results agree with these reports.

Fariss et al. (7) demonstrated that conflicting results of the effect of extracellular calcium on chemical toxicity were related to cellular vitamin E content. However, in our system, both calcium and vitamin $\mathrm{E}$ independently affected hepatocyte viability and cellular lipid peroxide content after cold storage and reculture. Cellular glutathione content (GSH + GSSG) decreased steadily during hypothermic preservation with Euro-Collins solution $(15 \mathrm{hr}, 42 \% ; 24$ hr, 22\%; both $P<0.001$ ). Glutathione is known to provide a defense system against lipid peroxidation (1), and Younes and Siegers (28) demonstrated that glutathione depletion per se increased spontaneous lipid peroxidation in rat liver homogenate. Therefore, it is suggested that glutathione depletion during hypothermic preservation causes lipid peroxidation in hepatocytes, which leads to cell injury and ultimately to cell death. When $0.8 \mathrm{mM}$ of calcium was added to the preservation solution, a significantly greater amount of glutathione was maintained in the hepatocytes $(P<0.001$, both 15-hr and 24-hr preservation). Fariss et al. (6) reported that hepatocytes cultured with calcium maintained their glutathione content but those without calcium lost it gradually. Graf and Sies (9) demonstrated with the rat liver perfusion system that omission of calcium from the perfusate was accompanied by a substantial increase in glutathione release from the liver into the perfusate. Our results are similar to those of these reports. This preservation of glutathione during cold storage is thought to lead to suppression of lipid peroxidation and of ultimate cell death caused by hypothermic preservation and reculture. 
Magnesium was included in Collins solution (3), but contradictory opinions exist as to the effectiveness of magnesium $(4,12$, 14). Euro-Collins solution, which does not contain magnesium, offers satisfactory preservation in experimental kidney transplantation (5) and is widely used throughout the world. In our system, magnesium did have a favorable effect on hepatocyte viability after cold storage and reculture, but the effect was much less than that of calcium.

Whether our results with cultured hepatocytes can be applied to the liver as an organ is not certain. Cultured hepatocytes are an excellent experimental model in that many identical samples from one liver can easily be obtained. However, besides hepatocytes, the liver has various kinds of cells, such as vascular endothelial cells and reticuloendothelial cells, which may express different responses to extracellular calcium during cold storage and reculture. The next step would be to test preservation of the liver as a whole organ with or without calcium. This study, in the meantime, demonstrated the favorable effect of extracellular calcium on hepatocytes during hypothermic preservation and reculture.

\section{ACKNOWLEDGMENT}

This work was partly supported by the Ministry of Education, Culture and Science, Japan.

\section{REFERENCES}

1. Chance, B., Boveris, A., Nakase, Y., and Sies, H. Hydroperoxide metabolism: An overview. In "Functions of Glutathione in Liver and Kidney"' (H. Sies and A. Wendel, Eds.), pp. 95-105. Springer-Verlag, New York, 1978.

2. Charest, R., Blackmore, P. F., and Berton, B. Changes in free cytosolic $\mathrm{Ca}^{2}+$ in hepatocytes following $\alpha_{1}$-adrenergic stimulation. Studies on Quin-2-loaded hepatocytes. J. Biol. Chem. 258, 8769-8773 (1983).

3. Collins, G. M., Bravo-Shugarman, M., and Terasaki, P. I. Kidney preservation for transportation. Initial perfusion and 30 hours ice storage. Lancet 2, 1219-1222 (1969).

4. Downes, G., Hoffman, R., Huang, J., and Belzer, F. O. Mechanism of action of washout solutions for kidney preservation. Transplantation 16 , 46-53 (1973).

5. Dreikorn, K., Horsch, R., and RohI, L. 48- to 96hour preservation of canine kidneys by initial perfusion and hypothermic storage using the Euro-Collins solution. Eur. Urol. 6, 221-224 (1980).

6. Fariss, M. W., Olafsdottir, K., and Reed, D. J. Extracellular calcium protects isolated rat hepatocytes from injury. Biochem. Biophys. Res. Commun. 121, 102-110 (1984).

7. Fariss, M. W., Pascoe, G. A., and Reed, D. J. Vitamin $E$ reversal of the effect of extracellular calcium on chemically induced toxicity in hepatocytes. Science 227, 751-754 (1985).

8. Fujimori, T., Monden, M., Umeshita, K., Sakai, H., Okamura, J., and Mori, T. Role of calcium in anoxia-induced liver cell death in culture. In "Cytoprotection and Cytobiology"' (M. Tsuchiya, Ed.), Vol. 3, pp. 127-136. Excerpta Medica, Amsterdam, 1985.

9. Graf, P., and Sies, H. Hepatic glutathione release upon decreases of extracellular calcium concentration. Biochem. Pharmacol. 35, 2832-2833 (1986).

10. Granger, D. N., Rutili, G., and McCord, J. M. Superoxide radicals in feline intestinal ischemia. Gastroenterology 81, 22-29 (1981).

11. Green, C. J., Healing, G., Lunec, J., Fuller, B. J., and Simpkin, S. Evidence of free radical-induced damage in rabbit kidneys after simple hypothermic preservation and auto-transplantation. Transplantation 41, 161-165 (1986).

12. Green, C. J., and Pegg, D. E. Mechanism of action of "intracellular" renal preservation solutions. World. J. Surg. 3, 115-120 (1979).

13. Hochachka, P. W. Defense strategies against hypoxia and hypothermia. Science 231, 234-241 (1986).

14. Jablonski, P., Howden, B., Marshall, V., and Scott, D. Evaluation of citrate flushing solution using the isolated perfused rat kidney. Transplantation 30, 239-243 (1980).

15. Masugi, F., and Nakamura, T. Measurement of thiobarbituric acid value in liver homogenate solubilized with sodium dodecyl sulfate and variation of the values affected by vitamin $E$ and drugs. Vitamins 51, 21-29 (1977).

16. Monden, M., and Fortner, J: G. Twenty-four- and 48-hour canine liver preservation by simple hypothermia with prostacyclin. Ann. Surg. 196, 38-42 (1982)

17. Murphy, E., Coll, K., Rich, T., and Williamson J. R. Hormonal effect on calcium homeostasis in isolated hepatocytes. J. Biol. Chem. 255, 6600-6008 (1980).

18. Pegg, D. E. Organ preservation. Surg. Clin. North Amer. 66, 617-632 (1986). 
19. Schanne, F. A. X., Kane, A. B., Young, E. E., and Farber, J. L. Calcium dependence of toxic cell death: A final common pathway. Science 206, 700-702 (1979).

20. Seglen, P. O. Preparation of isolated rat liver cells. In "Methods in Cell Biology" (D. M. Prescott, Ed.), Vol. 13, pp. 29-83. Academic Press, New York, 1976.

21. Smith, M. T., Thor, H., and Orrenius, S. Toxic injury to isolated hepatocytes is not dependent on extracellular calcium. Science 213, 1257-1259 (1981).

22. Starzl, T. E., Iwatsuki, S., and Shaw, B. W. Transplantation of the human liver. In "Maingot's abdominal operations" (S. I. Schwartz and H. Ellis, Eds.) 8th ed., pp. 1687-1722, Appleton-Century-Crofts, Norwalk, CT, 1985.

23. Starzl, T. E., Iwatsuki, S., Van Thiel, D. H., Gartner, J. C., Zitelli, B. J., Malatack, J. J., Schade, R. R., Shaw, B. W., Hakala, T. R., Rosenthal, J. T., and Porter, K. A. Evolution of liver transplantation. Hepatology 2, 614-636 (1982).
24. Tappel, A. L. Vitamin E and free radical peroxidation of lipids. Ann. NY Acad. Sci. 203, 12-28 (1972).

25. Tietze, F. Enzymatic method for quantitative determination of nanogram amounts of total and oxidized glutathione: Application to mammalian blood and other tissues. Anal. Biochem. 27, 502-522 (1969).

26. Trump, B. E., Berezesky, I. K., and Cowley, R. A. The cellular and subcellular characteristics of acute and chronic injury with emphasis on the role of calcium. In "Pathophysiology of Shock, Anoxia, and Ischemia" (R. A. Cowley and B. F. Trump, Eds.), pp. 6-46. Williams \& Wilkins, Baltimore, MD 1982.

27. Williams, G. M., Weisburger, E. K., and Weisburger, J. H. Isolation and long-term cell culture of epithelial-like cells from rat liver. Exp. Cell Res. 69, 106-112 (1971).

28. Younes, M., and Siegers, C. P. Lipid peroxidation as consequence of glutathione depletion in rat and mouse liver. Res. Commun. Chem. Pathol. Pharmacol. 27, 119-128 (1980). 